\title{
To Buy or Not to Buy? The Moral Relevance of the Individual Demand in Everyday Purchase Situations
}

\author{
Bernward Gesang ${ }^{1} \cdot$ Rebecca Ullrich ${ }^{1}$
}

Accepted: 18 March 2020 / Published online: 29 April 2020

(C) The Author(s) 2020

\begin{abstract}
The question of the moral relevance of the individual demand is fundamental to many purchase decisions of daily consumer life. Can a single purchase make a difference for the better or worse? Each individual consumer could argue that companies are unlikely to adjust their production due to one single item more or less being sold. He might therefore decide not to change his consumption behavior but instead to rely on the effort of others, a pattern commonly referred to as collective action problem. In this article, we study collective action problems with regard to everyday purchase situations. We base our discussion on Shelly Kagan's famous article "Do I make a difference?" and critically discuss a central assumption of his model: the symmetric relationship between supply and demand. We find that Kagan's solution to collective action problems is not true a priori but has to be evaluated in certain empirical surroundings. We therefore discuss the approach in the context of the European meat market and demonstrate that Kagan's argument does not provide a universal solution to cases of meat purchasing. We conclude with an outlook regarding the role of consumer ethics.
\end{abstract}

Keywords Collective action · Consequentialism · Expected utility $\cdot$ Consumer ethics $\cdot$ Meat consumption

\section{Do I Make a Difference?}

We are living in an increasingly globalized and interconnected world - a development that alters not only our habits of living and communicating but also our consumption behavior. Consider an everyday purchase situation like grocery shopping in a supermarket. Due to global

Bernward Gesang

Bernward.Gesang@uni-mannheim.de

Rebecca Ullrich

rebeccaullrich@aol.com

1 Philosophical Seminar Mannheim, Mannheim, Germany 
value chains, a broad range of products is available at remarkably affordable prices. While the individual consumer benefits from this convenience, he is probably aware of the downsides associated with global value chains such as unsustainable production practices, animal suffering and worker exploitation.

The avoidance of such negative repercussions constitutes a goal that perhaps can be achieved if a sufficient number of people collaborate by changing their purchasing habits. Companies might react to changes in large-scale consumption patterns and consumer preferences, which can be made plausible by the rise of the fair trade movement or by successful consumer boycotts (O’Rourke 2012). Each individual consumer, however, might decide not to change anything and instead to rely on the efforts of others. He could argue that companies are unlikely to adjust their production due to one single item more or less being sold, so that his purchase doesn't make any difference.

The aforementioned scenario constitutes a so-called problem of collective action (see e.g. Taylor 1987) or collective harm case (Nefsky 2015): on an individual level, a single act does not seem to make much of a difference, yet on a collective level accumulated actions result in harm to others — be it to people or to animals.

In this article, we study problems of collective action in the context of purchase situations. With my purchase, can I make any difference for the better or worse? Am I morally obliged to abstain from certain purchases? This article's research question Q can be precisely articulated as follows:

Q: Is it possible that many purchase actions together make a difference in terms of welfare, but no single purchase action makes any (positive or negative) difference in terms of welfare?

To study Q, we will refer to consequentialism as a normative framework. Consequentialism evaluates actions on the basis of their consequences. Problems of collective action as described in $\mathrm{Q}$ pose a fundamental challenge to a consequentialist rationale - that makes consequentialism interesting as a framework for our research (further arguments for our choice of consequentialism: Gesang 2005). If a single action does not bear any negative consequences or no consequences at all, act-consequentialism cannot morally condemn the action as illustrated by Shelly Kagan:

For if there are indeed cases that have this sort of structure $(\ldots)$ then consequentialism appears to fail even in its own favored terrain, where we are concerned with consequences $(\ldots)$. Intuitively $(\ldots)$ the acts in question need to be condemned because of the results that eventuate from everyone's performing them. (... ) Yet despite this, it seems as though the consequentialist simply isn't in a position to condemn the relevant acts ( ... ) The problem, in effect, is this: consequentialism condemns my act only when my act makes a difference. But in the kind of cases we are imagining, my act makes no difference. (Kagan 2011).

In the following, we will first of all summarize Shelly Kagan's solution approach to the aforementioned problem because it is the best consequentialist approach known to us, following a broad tradition (compare: Singer 1980; Parfit 1987; Matheny 2002). Kagan provides a positive answer to $\mathrm{Q}$ by performing an expected utility analysis which yields a negative expected utility for the single meat purchase. He concludes that each purchase can make a difference for the worse and thus can be condemned by a consequentialist rationale. Having outlined Kagan's line of argument, we then reveal the underlying assumptions of his model, such as a symmetric relation between supply and demand. Finally, we provide a detailed analysis of the European meat industry and find that Kagan's argument does not provide a universal solution to all cases of meat purchasing. 


\section{Solution Approach: S. Kagan}

Philosopher Shelly Kagan has recently actualized a tradition that aims to provide a standardsolution to the aforementioned problem of consequentialism and collective action (Singer 1980; Parfit 1987; Matheny 2002). In his article "Do I Make a Difference?" he argues that all collective action problems inherit a single (or several) threshold(s). Before this threshold is reached, several individual acts may occur without producing any harm. Once the threshold has been reached, a single additional action triggers the harmful result. It therefore holds true that while "most acts make no difference, [...] some single act makes a great deal of difference" (Kagan 2011). Kagan refers to such cases as triggering cases.

In order to illustrate a triggering case in daily consumption choices, Kagan uses the example of purchasing chicken. He assumes that chickens are raised and slaughtered on a chicken farm before they are delivered to the butcher's counter of a supermarket. At first sight, the purchase of an individual chicken does not seem to make any difference. The chicken is already dead when it arrives at the supermarket; thus the harm has already been created and cannot be attributed to the act of purchasing. Nevertheless, a single chicken purchase might trigger the order (and therefore the death) of new chickens. In Kagan's scenario, the supermarket does not order a new chicken for every chicken sold. Instead, it orders in fixed cycles: once $T$ chickens have been sold, $T$ additional chickens are reordered. The chicken farm reacts to the supermarket's order; i.e. it kills the corresponding number of chickens and hatches $T$ new eggs. The scenario resembles a triggering case in which every $T^{\text {th }}$ purchase constitutes a triggering action. If $T$ equals 25 , for instance, then the 25th, 50th, 75th etc. chicken purchase will each trigger the death of 25 chickens.

For his analysis, Kagan focuses on the cohort size, i.e. the number of people buying chickens (assumption: 1 chicken per person) at a given store on a particular day. Here, two scenarios can be distinguished:

\section{I) The cohort size is equal to $T$ (or a multiple of $T$ )}

If exactly $T$ (or $2 T, 3 T$ etc.) chickens have been sold, each chicken purchase can be directly linked to the harm associated with the death of the chickens. If one consumer had not made a purchase, the threshold of $T$ would not have been reached, and thus no additional $T$ chickens would have been ordered and killed. As this holds true for each individual consumer, it can be concluded that each purchase makes a morally relevant difference.

\section{II) The cohort size is not equal to $T$ (or a multiple of T)}

In this scenario, the individual purchase can no longer be related to the death of the chickens. Even if a single consumer had refrained from his purchase, still the same number of chickens would have been ordered and killed.

The individual consumer does not know the size of his cohort and thus has no idea whether he is facing scenario I or II. In order to account for this problem, Kagan uses the concept of expected utility (EUT). The EUT is the sum of the utilities of outcomes of an act multiplied by the respective probabilities that these outcomes will become real (Briggs 2016):

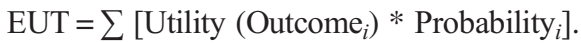

In relation to the chicken example, the (positive) utility associated with the purchase consists in the pleasure that can be derived from consuming the chicken. The death of the chicken constitutes a disutility that needs to be considered as well. 
EUT one chicken $=$ Expected Pleasure $(E P)-$ Expected Harm $(E H)$.

Kagan assumes the harm created by the killing of the chicken to be greater than the pleasure derived from its consumption. Having made those assumptions, the EUT of buying a chicken can now be calculated as follows:

In any case, the pleasure (EP) associated with the purchase equals the consumption of one chicken. The harm related to the purchase depends on the size of the cohort the consumer is part of. If the cohort size equals (a multiple of) $T$ (scenario I), the purchase is associated with the death of $T$ additional chickens. If not (scenario II), no harm can be attributed to the purchase. While the former is relatively unlikely (corresponding probability $\frac{1}{T}$ ), the latter is by far the more probable scenario (corresponding probability $\frac{T-1}{T}$ ). Both scenarios need to be taken into account when calculating EH. As indicated in the calculation, it turns out that EH consists of exactly one dead chicken.

In a final step, EP can be offset against EH. As the pleasure of consuming the chicken does not outweigh the harm created by the killing (per assumption), the EUT will doubtlessly be negative.

$$
\begin{gathered}
\mathrm{EUT}_{\text {Purchase }}=\mathrm{EP}_{\text {Purchase }}-\mathrm{EH}_{\text {Purchase }} \mid\left(\text { given } \mathrm{EP}_{\text {Purchase }}<\mathrm{EH}_{\text {Purchase }}\right) . \\
\mathrm{EUT}_{\text {Purchase }}<0 .
\end{gathered}
$$

Kagan concludes that not buying the chicken constitutes the superior alternative compared to buying it.

All in all, Kagan provides a positive answer to Q: All problems that emerge from collective buying patterns inherit a threshold which can be crossed by a single purchase. Crossing the threshold induces the production of additional products (chickens, sweatshirts etc.) and thus the creation of additional product-related harm. Even though the consumer does not know whether his particular purchase will actually trigger new production (or more precisely: whether he is part of a cohort of the relevant size), he knows that this could be the case. Overall, it is the possibility of causing harm that yields a negative EUT and thereby makes the purchase compared to not buying morally unacceptable.

\section{The Symmetry Thesis}

In Kagan's argument, the $T^{\text {th }}$ purchase triggers the order (and thereby the production) of additional $T$ products. For each individual customer, the probability of setting off the trigger is $\frac{1}{T}$ while the maximum amount of harm generated by the triggering action is exactly $T$. If $T$ is, for instance, 10 , each individual has a $\frac{1}{10}$ chance to be responsible for the death of 10 additional chickens. If Tis equal to 1000, on the contrary, the chance of setting off the trigger is $\frac{1}{1,000}$ and the associated harm would consist in the death of 1000 additional chickens. Note that if $T$ increases [decreases], the probability of setting off the trigger becomes smaller [larger], while the harm associated with the triggering action increases [decreases] (see also Fig. 1). For each individual action, the probability of setting off the trigger moves in inverse proportion to the amount of harm that can potentially be caused by this action (Matheny 2002). This relation is a key feature of Kagan's argument and is also referred to as the "symmetry thesis" (Gesang 2017). The symmetry thesis has a substantial impact on the EUT calculation: due to the 
relationship between the triggering number and the caused harm, $T$ is canceled out in the calculation (as it appears in both the numerator and denominator) and thus the EUT remains constant, independently of the actual value of $T$.

A critique of the symmetry thesis is also offered by Julia Nefsky: "There is no guarantee that the expected utility will come out negative in every triggering case. Whether it does or not depends on the probabilities and on the goodness and badness of the relevant consequences." (Nefsky 2012; cf. Harris and Galvin 2012). One of the present authors has shown that the symmetry thesis fails in context of climate ethics (Gesang 2017).

Kagan defends his points empirically by the symmetry thesis. In addition he gives an a priori argument, which one of the authors discusses in detail elsewhere (Gesang 2017). A short overview may be helpful: Let us begin with Parfits harmless torturer problem. In the harmless torturer case it is questionable whether it is morally right to be one of a thousand persons who, by pressing a button, makes a very small contribution to increasing the electrical voltage to which another person is being subjected and which, when viewed overall, causes this person great pain. But here the steps of each individual voltage increase should remain imperceptible to the sacrificed person. My pressing of the button does not cause any altered perception of pain in comparison to the amount of measured voltage caused by my predecessor (Parfit 1987).

But in comparison with the initial and final states of all individual contributions combined, there is a great difference in the degree of suffering. How can the difference between 0 and 1000 be so grave when all intermediate steps are harmless? Kagan believes that such cases do not exist (Kagan 2011). But that means that you can solve the problem of the sorites paradoxon which is here implicated (cf. Hyde 2018) easily in one direction. J. Nefsky offers a solution according to which the small increase in voltage caused by a protagonist in the example is not sufficient for leading to different perceptions of suffering. A minimal increase in voltage is simply not the right unit for causing perceptible suffering; just as in the Sorites problem, the grain of sand does not turn the heap into a hill (Nefsky 2012; cf. Wright 1975). So Kagans a

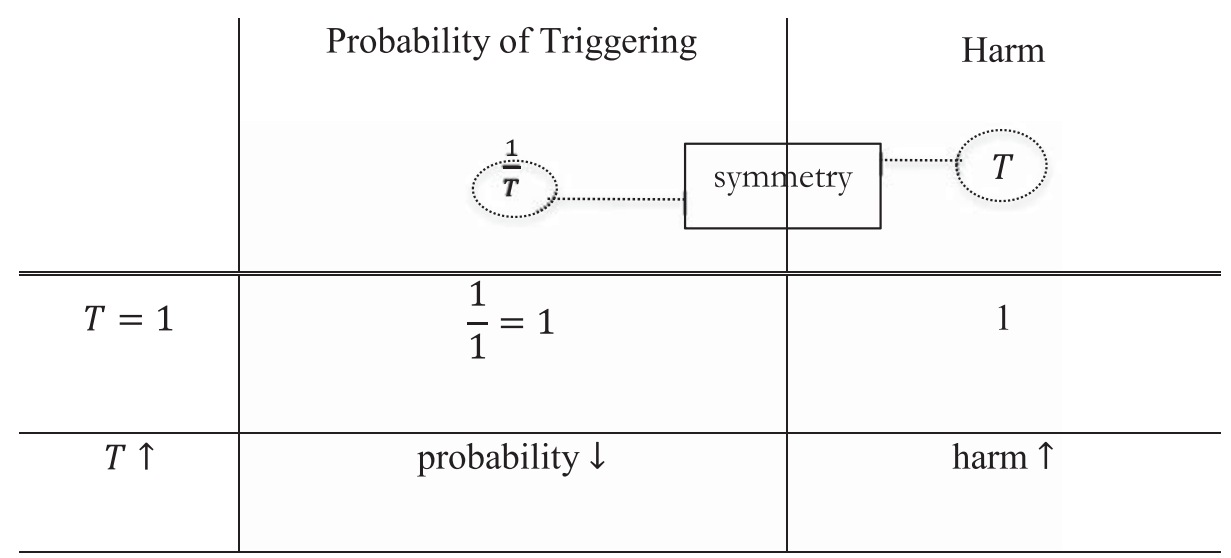

As $T$ increases [decreases], the probability of hitting the trigger decreases

[increases]. The harm associated with the triggering action, however, increases

[decreases].

Fig. 1 Symmetry thesis: disproportional relation between probability of triggering and caused harm 
priori point might not work - there exist alternatives. For Kagan remains the empirical symmetry thesis.

It becomes obvious that we need to take a closer look at how Kagan defends symmetry as actually prevailing in reality. Kagan justifies his symmetry assumption by referring to a supply-demand relationship. With regard to his example, he emphasizes that the butcher "adjusts his order to keep up with demand." (Kagan 2011). Furthermore, the butcher "neither wants to fall behind demand nor end up with larger numbers of unsold rotting chickens." (Kagan 2011). Kagan therefore concludes that "the number of chickens he [the butcher] orders is more or less the same as the number of purchases required before a new order is triggered." (Kagan 2011). Or, stated differently: supply will be more or less equal to demand.

In his line of argument, Kagan does not refer to any concepts from business or economics but instead introduces his scenario with the statement "presumably, it works something like this [ ...]. " (Kagan 2011). To us, this procedure is not convincing inasmuch as it lacks a solid foundation. In the following, we therefore want to shift perspectives and analyze Kagan's scenario from the viewpoint of business studies and economics.

\section{Supply and Demand}

In economic theory, supply and demand are the key forces at work in a market economy. The relationship between supply and demand determines prices in the economy, and thus ultimately the allocation of resources. If the supply is greater than the demand (and vice versa), there is a pressure on the price to change. Assume, for example, that the demand for a product suddenly drops. Supply will then be greater than demand and the price of the product will drop as well. At a lower price, more people will be willing to buy the product; i.e., demand increases again. At some point, there will be a price that balances supply and demand, a situation commonly referred to as market equilibrium (Mankiw and Taylor 2014).

Based on the law of supply and demand, can we assume that companies will automatically adjust their supply once they experience a change in demand? Not necessarily. First of all, we need to narrow down a time frame to be considered in our analysis. The question as to whether (and if so, how) individual demand affects supply is also a matter of time. In economic theory, two different conceptual time periods can be distinguished: the short term and the long run. The distinction between the different time periods bears direct relevance for a producer's supply decisions: In the short term, some factors of production ${ }^{1}$ are fixed and therefore cannot be changed (Mankiw and Taylor 2014). A production plant's capacity, for instance, is fixed and cannot be increased from one day to another. Consequently, if a company detects an increase in demand, it might not be able to increase its production levels accordingly in the short run. Similarly, if there is a drop in demand, the company might not be able to immediately cut back production as well. In the long run, all factors of production can be altered (Mankiw and Taylor 2014). Consequently, a firm is more flexible regarding its supply-related decisions in the long run. It could, for example, decide to open a new plant as a consequence of increased demand or to look for geographically new markets as a reaction to a drop in demand. In relation to Q it is therefore important to specify the time frame at issue. While a change in demand will probably not affect production levels in the short term, it might indeed in the long run.

\footnotetext{
${ }^{1}$ Factors of production are the resources or inputs needed in order to produce output, i.e. goods and services. Land, labor and capital constitute the most basic factors of production (Mankiw and Taylor 2014).
} 


\section{The Common Agricultural Policy}

To estimate long-term influences in Kagan's example, we need to consider the fact that the industry chosen by Kagan (the meat industry) is a very specific one. Meat is an agricultural product and is as such subject to a variety of political rules and regulations. These rules and regulations, in turn, depend on the geographic location of the corresponding market and differ significantly from country to country. In the following, we will focus on the particularities of the meat industry within the European Union. ${ }^{2}$ Literature has been emphasizing for decades the strong political influence that the European Union exerts on the agricultural production of such products as meat (Henrichsmeyer and Witzke 1991).

In the 1980s, for instance, it was common to systematically subsidize meat production in the EU with up to 15 billion euros annually. (http://www.spiegel.de/wirtschaft/service/agrarsubventionender-eu-werden-viel-zu-spaet-abgeschafft-a-944019.html). In 2014, direct subsidies related to meat production in the EU were finally abolished (with the exception of France, Austria and Denmark) (http://www.bauernverband.de/43-gemeinsameagrarpolitik-gap-erste-saeule). As of now, there are still some measures of state support in place (e.g. the VAT reduction for meat in Germany), yet with a significantly lower impact.

However, the decisive aspect in this regard is the fact that meat subsidies have been abolished because they were no longer required by the meat industry. Former EU minister of agriculture Dacian Ciolos has pointed to the fact that at some point, industry characteristics might change again such that the decision might be reversed (https://info.brot-fuer-die-welt. de/blog/exportsubventionen-afrika-sind-nicht-abgeschafft; https://germanwatch.org/de/9079). We therefore conclude that meat subsidies have currently been paused rather than irreversibly abolished.

This producer-friendly attitude also reflects the official definition of EU agricultural policy as a whole: in order to organize agricultural policy within the EU, member states have agreed on a socalled Common Agricultural Policy (CAP), which steers and regulates the supply of agricultural products. The goal of the CAP is to ensure "a decent standard of living for farmers, at the same time as setting requirements for animal health and welfare, environmental protection and food safety." (https://ec.europa.eu/agriculture/cap-overview_en) In relation to our research question Q, the CAP is a relevant factor to be considered in our analysis. The steering force of the CAP alters the rules of the game and substantially impacts upon farmers' production-related decisions (e.g. what / how / how much to produce). All in all, the subsidies and governmental support measures related to the meat industry serve as a "safety net" that makes producers less vulnerable to fluctuations in demand. In the event of crises, some sort of governmental interference can be expected.

Whether this influence is long- or short-term depends on how long these political "market distortions" are maintained. What we see is that market distortions have been present for quite a while. In addition, lobbying continues to shape decisions related to agricultural policy. As a consequence, a single purchase is unlikely to have an effect on production levels in the industry. As long as these distortions are present, there is no need to balance supply and demand, which would be necessary in order to influence small fluctuations in demand such as those caused by individual buying.

It is therefore wrong to establish correlations between supply and demand that disregard this aspect. Thus, there is the thesis of Norwood and Lusk that through the renunciation of any

\footnotetext{
${ }^{2}$ As compared to Kagan, who probably would have chosen the American meat industry for any empirical proofs; this, however, does not affect the point we are trying to make in the following section.
} 
one egg, the total production will drop by 0.91 eggs. Similarly, not consuming one $\mathrm{kg}$ of beef will lead to $0.68 \mathrm{~kg}$ less beef being produced (Norwood and Lusk 2011): "In reality if Frank eats one more chicken, total chicken consumption will increase by slightly less than one chicken. As Frank demands more chicken the price will slightly rise, inducing others to eat less." (Norwood and Lusk 2011). However, Norwood and Lusk only take into consideration the relationships among supply, stock, demand and price: "The impact of a single individual's choice, however, is complex. The effect of abstaining from eating poultry on the number of animals raised for chicken meat depends on the size of the population of farm animals and on the supply and demand for chicken." (Norwood and Lusk 2011). Just as is the case with Kagan, Norwood and Lusk do not include institutions that can potentially compensate for demand shortages in their analysis.

Even though state intervention might play an important role, it does not totally level off the relevance of demand for meat. Finally, demand plays a role in determining which laws and regulations are kept in place. Assume there was a sudden drop in demand: the more severe this drop is in terms of scope and duration, the more expensive state assistance will be. At some point, states might no longer be able to compensate for the full drop in demand, so that production levels would finally decrease. Whether this would actually happen would mainly depend on power-political calculations. There might be a party A representing the interests of farmers. This party would probably defend state aid regardless of the costs associated with the measures. Party B, on the other hand, aims at stopping state aid no matter how severe potential demand crises might be. Whether party A or B dominates in the end does not depend on any triggering points or thresholds, but on power politics. But it could also be different, so that current demand figures are important arguments. Overall, those mechanisms are very difficult to anticipate and it is certainly not possible to calculate them in the form of an expected utility analysis.

In order to make a targeted decision, an empirical evaluation must therefore be carried out regarding the extent to which demand has an impact on a specific product and how strong the lobby is that protects this product. In each case, a check has to be made as to whether the producer's reaction is so "fine-grained" that every single purchase counts, at least as one that may possibly (given the current political constellations) exceed or fall below a threshold value. ${ }^{3}$ In view of the fact that such complex mechanisms based on many players are involved, the prognosis is not self-evident — and sometimes unlikely — that a single purchase can have an effect. In any case, Kagan's a priori suppression of market specifics must be questioned, and that is our main finding. Each product has different dimensions and is to be examined separately for its demand elasticity. What follows from this is that not every single meat purchase really has an impact on the number of animals raised and killed in total. The relationships among CAP, political powers and markets have to be taken into consideration.

\section{Conclusions and Outlook}

1. Kagan's argument is convincing if (and only if) we are facing a market in which supply and demand balance each other.

2. Supply and demand balance each other in a market where the symmetry thesis is met.

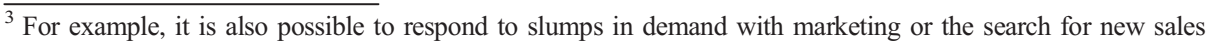
markets.
} 
3. In the EU meat market, the symmetry thesis is not met because of political regulations and ensuing conclusions drawn by the producers.

4. In the EU meat market, we encounter a market in which supply and demand do not balance each other.

C. Kagan's argument is not convincing for the EU meat market.

One must give a negative answer to $\mathrm{Q}$.

In a final remark, a brief outlook on conscious consumer behavior as a driver of economic change is to be given. As a consequence of this work, one could think that it is infinitely difficult to make the right decisions here, so that one would rather not commit oneself at all. This conclusion is a fallacy. In fact, it is difficult to decide whether and when an individual purchase has a positive effect. This effect can often be achieved more effectively by donating to charities the money that could be used for the conscious consumption of alternative products (cf. MacAskill 2015). Donations have the advantage that an individual action can also help without collective cooperation and thus have a direct effect compared to ethical consumption. Conscious consumption makes a positive difference to the world only if enough consumers participate. In contrast, a donation to an effective charity can make a difference in terms of welfare, no matter how many people participate., for example it can bring it about that a person is cured from blindness. Those who have spare resources should therefore donate their money to effective charities instead of spending it on more expensive consumption. Donations to charity even make it possible to combine sure welfare gains with possible successes of collective actions. For example, if I secure the livelihood of small farmers in the rain forest, I directly help these farmers. In addition, I prevent them from selling their (or their communities) land to large corporations that would destroy the rain forest. I thereby help protecting species diversity and I may help fight climate change, provided that a sufficient number of small farmers receives that kind of support.

In some cases, though, my cooperation in conscious consumption is costless to me or I can make welfare gains with it. If so, I should cooperate. For example, it doesn't make a difference for me whether I install Google or Ecosia (a search engine that uses its revenues from advertisement for reforestation) on my computer, but it does make a difference to the world.

Thus, the above result about the partial powerlessness of the individual consumer is exploited constructively. It does not lead us to conclude from a lack of influence that we cannot change anything and must therefore maintain the status quo. Rather, it serves as an indication that resources can be used more effectively in other places than for individual consumption (MacAskill 2015; about problems with this see Budolfson and Spears 2019). One could also conclude, of course, that the whole argumentation shows that consequentialism fails as a framework, since it does not prohibit what is evidently forbidden. Other models (Kutz 2000; Schwartz 2017) might be more useful for consumer ethics. This fundamental decision exceeds the scope of this paper.

Another reaction to the findings presented is to not focus on one's own purchasing behavior, but on the political commitment of the citizens (Maltais 2013). This is certainly a possible reaction to the situation described, but it is a difficult task to demonstrate that the individual is more influential as a political actor or voter than as a consumer (Downs 1957). This project also goes beyond our chosen perspective (see Gesang 2020).

Funding Information Open Access funding provided by Projekt DEAL. 
Open Access This article is licensed under a Creative Commons Attribution 4.0 International License, which permits use, sharing, adaptation, distribution and reproduction in any medium or format, as long as you give appropriate credit to the original author(s) and the source, provide a link to the Creative Commons licence, and indicate if changes were made. The images or other third party material in this article are included in the article's Creative Commons licence, unless indicated otherwise in a credit line to the material. If material is not included in the article's Creative Commons licence and your intended use is not permitted by statutory regulation or exceeds the permitted use, you will need to obtain permission directly from the copyright holder. To view a copy of this licence, visit http://creativecommons.org/licenses/by/4.0/.

\section{References}

Briggs, Rachael. 2016. Normative theories of rational choice: Expected utility. Stanford Encyclopedia of Philosophy (Winter 2016 Edition), E.N. Zalta (ed.). https://plato.stanford.edu/archives/spr2017 /entries/rationality-normative-utility.

Budolfson, Mark, and Dean Spears. 2019. The hidden zero problem: Effective Altruism and barriers to marginal impact. In Hilary greaves and Theron Pummer, ed. Effective Altruism, 184-201. Oxford: Oxford University Press.

Downs, Anthony. 1957. An economic theory of democracy. New York: Harper \& Brothers.

Gesang, Bernward. 2005. Utilitarianism with a human face. The Journal of Value Inquiry 39: 169-181.

Gesang, Bernward. 2017. Climate change: Do I make a difference? Environmental Ethics 9: 3-19.

Gesang, Bernward. 2020. In press. Hanser-Verlag: Mit kühlem Kopf. Vom Nutzen der Philosophie für die Klimadebatte. München.

Harris, John Richard, and Richard Galvin. 2012. 'Pass the cocoamone, please': Causal impotence, opportunistic vegetarianism and act-utilitarianism. Ethics, Policy \& Environment 15: 368-383.

Henrichsmeyer, Wilhem, and Heinz-Peter Witzke. 1991. Agrarpolitik Vol. 1 -Agrarökonomische Grundlagen. Stuttgart: UTB.

Hyde, Dominic. 2018. "Sorites paradox", The Stanford Encyclopedia of Philosophy (Winter 2016 Edition), Edward N. Zalta (ed.). https://plato.stanford.edu/archives/win2016/entries/sorites-paradox.

Kagan, Shelly. 2011. Do I make a difference? Philosophy \& Public Affairs. https://doi.org/10.1111/j.10884963.2011.01203.x.

Kutz, Christopher. 2000. Complicity: Ethics and law for a collective age. Cambridge: Cambridge University Press.

MacAskill, William. 2015. Doing good better: How effective Altruism can help you make a difference. New York: Random House.

Maltais, Aaron. 2013. Radically non-ideal climate politics. Environmental Values 22: 589-608.

Mankiw, Nicholas Gregory, and Mark P. Taylor. 2014. Economics. 3rd ed. Andover: Cengage Learning EMEA.

Matheny, Gaverick. 2002. Expected utility, contributory causation, and vegetarianism. Journal of Applied Philosophy 19: 293-297.

Nefsky, Julia. 2012. Consequentialism and the problem of collective harm: A reply to Kagan. Philosophy \& Public Affairs 39: 364-395.

Nefsky, Julia. 2015. Fairness, participation and the real problem of collective harm. Oxford Studies in Normative Ethics. https://doi.org/10.1093/acprof:oso/9780198744665.001.0001.

Norwood, F. Bailey, and Jayson L. Lusk. 2011. Compassion, by the pound: The economics of farm animal welfare. Oxford: Oxford University Press.

O'Rourke, Dara. 2012. Shopping for good. Cambridge: MIT Press.

Parfit, Derek. 1987. Reasons and persons. New York: Oxford University Press.

Schwartz, David T. 2017. Consumig choices. Lanham: Rowman \& Littlefield.

Singer, Peter. 1980. Utilitarianism and vegetarianism. Philosophy \& Public Affairs 9: 325-337.

Taylor, Michael. 1987. The possibility of cooperation. Cambridge, New York, Paris: Cambridge University Press.

Wright, Crispin. 1975. On the coherence of vague predicates. Synthese 30: 325-365.

Publisher's Note Springer Nature remains neutral with regard to jurisdictional claims in published maps and institutional affiliations. 